\title{
Masculinidades em Trânsito: Processos Identitários de Motoboys em Belo Horizonte - MG
}

\author{
Gregório Ribeiro de Miranda ${ }^{1, *}$ \\ Orcid.org/0000-0003-1965-4226 \\ Adriano Roberto Afonso do Nascimento ${ }^{1}$ \\ Orcid.org/0000-0002-7752-0114
}

${ }^{1}$ Universidade Federal de Minas Gerais, Belo Horizonte, MG, Brasil

\begin{abstract}
Resumo
Os motoboys têm participação significativa na elevação das taxas de acidente e mortalidade no trânsito e compartilham do perfil geral de motociclistas no país: são homens de baixa renda. O presente trabalho, baseado na Teoria da Identidade Social, teve como objetivo identificar e analisar como motoboys de Belo Horizonte/MG concebem diferentes versões de masculinidade e que relações essas podem manter com a forma como se veem, se sentem e se comportam como motociclistas. Para tanto, realizou-se dez entrevistas semiestruturadas com motoboys moradores de Belo Horizonte, que foram analisadas através da técnica de análise de conteúdo. Os entrevistados demonstraram compartilhar de um ideal permeado por valores masculinos: um sujeito competente, responsável, heterossexual, ousado, destemido, independente e dominante. Apesar de reconhecerem conviver com muitos riscos no trânsito, os entrevistados em grande medida se julgam invulneráveis a eles. O bom motoqueiro não é apenas um bom condutor e bom trabalhador, é um homem excepcional.
\end{abstract}

Palavras-chave: Masculinidade, identidade social, motoboys.

\section{Masculinities in Traffic: Identity Processes of Motorcycle Deliverymen in Belo Horizonte, Brazil}

\begin{abstract}
Motorcycle deliverymen/couriers share a significant part of the blame for the upsurge in traffic accidents and mortality rates in Brazil, and they exhibit the same general profile that other Brazilian motorcyclists exhibit: low-income males. Based on Social Identity Theory, the present study seeks to identify and investigate both the manner in which motorcycle deliverymen in Belo Horizonte (Minas Gerais, Brazil) perceive the various conceptions of masculinity and the way in which such conceptions potentially correlate with how such bikers view themselves, feel and behave as motorcyclists. In order to achieve the above objectives, we conducted ten semi-structured interviews with motorcycle couriers living in Belo Horizonte, analyzing the interviews via the content analysis method. Those interviewed revealed

Endereço para correspondência: Rua Lagoa Santa, 253, Bairro Carlos Prates, Belo Horizonte, MG, Brasil 30.710-090. E-mail: gribmir@gmail.com

O artigo é parte da dissertação de mestrado do primeiro autor, com apoio financeiro da Fundação de Amparo à

Pesquisa do Estado de Minas Gerais (FAPEMIG), sob orientação do segundo autor.
\end{abstract}


that they share a common ideal replete with male values: a guy that is competent, responsible, heterosexual, daring, fearless, independent and dominant. Although the men interviewed recognize that they face many traffic risks, they largely consider themselves invulnerable to such risks. A good biker is not merely a good driver and a hard worker, but also an exceptional man.

Keywords: Masculinity, social identity, motorcycle deliverymen.

\section{Masculinidades en Tránsito: Procesos Identitarios de Motomensajeros en Belo Horizonte - MG}

\section{Resumen}

Los motomensajeros tienen participación significativa en la elevación de las tasas de accidente y mortalidad en el tráfico y comparten del perfil general de motociclistas en el país: son hombres de baja rienda. El presente trabajo, basado en la Teoría de la Identidad Social, tubo como objetivo identificar y analizar como motomensajeros de Belo Horizonte/MG conciben diferentes versiones de masculinidad y cómo esas interactúan con la forma cómo se ven, se sienten y se comportan como motociclistas. Para tanto, se realizaron diez entrevistas semi-estructuradas con motomensajeros residentes en Belo Horizonte, que fueron analizadas a través de la técnica de Análisis de Contenido. Los entrevistados demostraron compartir de un ideal permeado por valores masculinos: un sujeto competente, responsable, heterosexual, osado, valiente, independente y dominante. Aunque reconozcan convivir con muchos riesgos en el tráfico, los entrevistados en gran medida se juzgan invulnerables a ellos. El buen motociclista no es solamente un buen conductor y buen trabajador, es un hombre excepcional.

Palabras clave: Masculinidad, identidad social, motomensajeros.

Historicamente recentes e ainda em plena ascendência, a popularização do carro e o boom das motocicletas em nossas metrópoles significaram importantes mudanças no cotidiano e foram apropriados de diferentes formas pela população. Mais do que meros meios de transporte, os veículos se tornaram fontes de renda para alguns e elementos centrais do estilo de vida para outros. No meio do caminho entre estas duas possibilidades estão os motociclistas profissionais, que se arriscam diariamente para suprir a crescente demanda por serviços de entrega. Nesse contexto, os homens foram os que mais desfrutaram das vantagens da motorização e, em contrapartida, de suas consequências negativas.

Nos registros do Sistema de Informações sobre Mortalidade (SIM), sintetizados por Waiselfisz (2013), observa-se que o número total de mortes no trânsito passou de 28.995 ao ano de 2000 para 43.256 em 2011, um aumento de $49,2 \%$ em 11 anos. O crescimento da frota de veículos e da mortalidade no trânsito, entretanto, não ocorreu de maneira equivalente entre as mo- dalidades de transporte. Ainda que seja supervalorizado culturalmente e tido como elemento essencial à vida moderna, o carro ainda é um bem de consumo de difícil acesso à maior parte da população brasileira que, na última década, tem optado cada vez mais pela motocicleta como meio de transporte.

Entre 1996 e 2010, enquanto a frota nacional de automóveis registrou um aumento de 133,5\%, a de motocicletas cresceu $491,1 \%$ (Waiselfisz, 2013). A variação nas taxas de mortalidade, segundo o autor, foi ainda mais discrepante, sofrendo um aumento de $87,5 \%$ entre motoristas e de $610 \%$ entre motociclistas, no mesmo período. Em suma, fatores como "(i) a baixa atratividade do transporte coletivo, (ii) o baixo custo das motocicletas, e (iii) sua habilidade para se deslocar nas congestionadas vias dos principais centros urbanos" (Ferreira, 2009, p. 15) parecem se sobrepor ao elevado risco associado ao uso do veículo.

Assim como as mortes no trânsito não são idênticas entre as modalidades de transporte, 
elas também se distribuem desigualmente entre a população. Dentre a diversidade de observações possíveis, uma é mais evidente: as taxas de mortalidade nas vias são tipicamente masculinas. O sexo masculino representou, em 2011, nada menos que $82,3 \%$ das vítimas letais de acidentes de trânsito no país (Waiselfisz, 2013). Sendo a categoria que mais morre, os motociclistas contam também com uma das taxas de mortalidade com maior composição masculina, atingindo a proporção de $89,7 \%$ no mesmo ano. Segundo o autor, os motociclistas constituem também o universo mais jovem, com média de 32,3 anos, e se fazem presentes nos domicílios mais pobres.

\section{Trânsito e Gênero}

Ainda que largamente evidenciada pela literatura, a dimensão de gênero é um dos elementos negligenciados no campo de pesquisa sobre o trânsito. A maior parte dos trabalhos realizados buscou explicar ou compreender o trânsito através da suposição de um condutor anônimo, descolado de suas relações sociais e desimpregnado de marcações de gênero. Talvez por se entender a vulnerabilidade masculina no trânsito como fato natural ou como efeito de causas externas, não se foi muito além da descrição do perfil masculino das taxas de motorização e mortalidade.

Alguns estudos nacionais, entretanto, realizaram esforços em apreender as construções de gênero que permeiam o contexto do trânsito. Os trabalhos de Figliuzzi (2008) e Lara (2007), por exemplo, mostraram que, para um mesmo objeto - o carro - são ressaltados aspectos diferentes segundo o gênero com que se relaciona. Além disso, corroboraram com a constatação de que tanto o carro quanto a mulher são submetidos, seja qual for o recorte metodológico, ao olhar masculino. $\mathrm{O}$ automóvel figura em nosso meio social, via de regra, como objeto de consumo masculino.

A pesquisa realizada por Souza (2001) apresenta o diferencial de ter se perguntado também sobre a forma como as mulheres jovens se apropriam do veículo, como o significam e que usos atribuem a ele. A autora revelou que homens e mulheres enfocaram elementos diferentes da mesma representação, concluindo que o com- portamento de risco no trânsito é mais bem valorizado e consequentemente mais frequente em rapazes.

A literatura internacional, por sua vez, conta com obras que procuraram elucidar a relação entre os gêneros, a cidade e os automóveis. Virginia Scharff (1992) demonstra, por exemplo, como as noções de gênero dos fabricantes de automóveis formataram até mesmo suas características mais básicas, afetando a forma como eram usados e as consequências de seu uso. Historicamente, argumenta, inovações concebidas para aprimorar a segurança, conforto e limpeza foram significadas como concessões à fragilidade feminina, mesmo que fossem úteis e urgentes para todos os motoristas e passageiros.

Analisando a emergência e função justificadora do estereótipo negativo da "mulher motorista", Berger (1992) argumenta que a eclosão da primeira guerra mundial tirou os homens estadunidenses de casa, mas deixou seus carros para trás, criando as condições para que as mulheres aprendessem a dirigir. A possibilidade, entretanto, da apropriação do automóvel pelas mulheres teria sido vista com preocupação pelos homens, que temiam que, com a liberdade conquistada, as mulheres rejeitassem seus maridos, filhos e lares.

Wachs (1992), por sua vez, insiste no papel central que o automóvel e a mobilidade têm na gênese e manutenção de um espaço urbano dicotomizado entre esferas masculinas e femininas. Tradicionalmente, argumenta, enquanto atribuímos à cidade características masculinas, como assertividade, atividades econômicas e criatividade intelectual, associamos o subúrbio à esfera feminina, à domesticidade, passividade, repouso, proximidade à natureza e a valores espirituais.

Para Keijzer (1998), no México, os mesmos atributos, valores, funções e condutas que uma cultura supõe essenciais ao homem, e que representam claras vantagens em relação à mulher, com o tempo, e ao estereotiparem-se, acabam implicando para esses mesmos homens (bem como a outros homens, às mulheres e às crianças) em altos custos para sua saúde. O autor, nesse sentido, foi preciso em propor a socializa- 
ção masculina como fator explicativo da sobremortalidade masculina, em que o trânsito figura entre as principais causas de morte.

Em seu conjunto, essas obras exploraram as relações entre gênero, mobilidade, violência no trânsito e vida cotidiana, bem como suas consequências, revelando uma diferença significativa da experiência de acesso à cidade e de exposição ao risco entre homens e mulheres. Outros trabalhos vão se ocupar de grupos específicos que têm a motocicleta como elemento central de identificação e são formados majoritariamente por homens: os motoclubes e os motociclistas profissionais.

\section{Masculinidades Sobre Duas Rodas}

Apesar do desafio que apresentam como tema de investigação, visto o distanciamento, suspeita e às vezes agressividade que destinam a não-membros, os motoclubes norte-americanos foram objeto de frutíferos estudos longitudinais (Hopper \& Moore, 1983, 1990; Wolf, 1991). De forma geral, os trabalhos mostraram que seus participantes têm em comum o "amor" pelas motocicletas, um forte senso de fraternidade (brotherhood) que os distingue dos demais motociclistas e um senso geral de não-pertencimento à sociedade convencional.

Os motoclubes norte-americanos são formados principalmente por homens entre 21 e 45 anos, com pouca educação formal e quase nenhuma mistura racial (Hopper \& Moore, 1983). Wolf (1991) encontrou também que a maioria de seus membros são oriundos de classes mais baixas de trabalhadores. Segundo o autor, a atratividade dos motoclubes ilegais para esses homens pode ser explicada pela oportunidade única que lhe oferecem de desenvolver uma identidade pessoal valorizada e sentida como autêntica.

Apesar da força e impacto do movimento de liberação das mulheres entre os anos sessenta e oitenta, o autor defende que as atitudes depreciativas dos membros de motoclubes em relação às mulheres se mantiveram inalteradas. Hopper e Moore (1990), no entanto, argumentaram que houve significativas mudanças no período: a subordinação das mulheres nos motoclubes teria se intensificado ainda mais. Elas, que sempre foram reduzidas a seu papel como parceiras sexuais, teriam sido definidas ao longo dos anos como trabalhadoras responsáveis por trazer dinheiro para o motoclube, principalmente como dançarinas em bares noturnos, mas também se prostituindo ou trabalhando em empregos comuns.

Os motoclubes brasileiros mantêm similaridades e diferenças em relação aos seus pares norte-americanos. De maneira geral, os estudos consultados reafirmaram a predominância masculina, mas formadas por homens de maior poder aquisitivo. Luz (2009) identificou nos motociclistas cariocas uma centralidade da motocicleta não só nos espaços dos motoclubes, mas na vida pessoal de cada sujeito. O motociclismo aparece, para seus entrevistados, como condição que não se escolhe e não se pode abandonar, um elemento intrínseco às suas trajetórias, presente desde a infância até o fim da vida. $\mathrm{O}$ "verdadeiro motociclista" é aquele que ama sua moto e demonstra ter com ela uma relação afetiva protetora, masculina. Através do zelo, carinho e ciúme, esses homens se relacionariam com um objeto feminilizado: a motocicleta, esta companheira bonita, frágil e desprotegida. Os membros de motoclubes entrevistados pelo autor, entretanto, foram refratários à noção de gangues, se embasando num ideário do motociclista contrário à violência, regido por regras e solidário com a população carente.

Fernandes (2012) também encontrou, em Salvador, grupos de motociclistas receptivos à interação com não-membros e adeptos de campanhas de solidariedade. Outros, entretanto, apresentaram uma postura exclusivista e segregadora, com restrições ao diálogo com pessoas estranhas ao grupo. A única coisa que unia grupos tão diferentes, argumenta, era (novamente) a "paixão" pelas motocicletas.

Considerando o conjunto maior da população, entretanto, é necessário admitir que um número muito maior de motociclistas brasileiros não tem condições financeiras para investir em motocicletas potentes e prestigiosas, nem como arcar com os altos custos das customizações e o sem-fim de acessórios. Para esses, a relação com a motocicleta é posta em prática por meio 
de atividades remuneradas. Numa malha viária saturada de automóveis, a maneira mais competitiva, rápida e barata, de se suprir a alta demanda por serviços de entrega tem sido através da motocicleta (Ferreira, 2009; Matos, 2008; Paes-Machado \& Riccio-Oliveira, 2009; Silva, Andrade, Soares, Nunes, \& Melchior, 2008).

Os motociclistas profissionais, mais conhecidos como motoboys ou motofretistas, em muitas cidades formam a maior parte do universo de motociclistas (Ferreira, 2009). Os motoboys têm participação importante também na elevação das taxas de acidente e mortalidade no trânsito. Em Belo Horizonte, dentre as vítimas que relataram estarem trabalhando no momento do acidente, 55,5\% eram motociclistas (Rodrigues, Ladeira, Pereira, \& Paula, 2005). Situação similar se repete em outros locais do país, como São Paulo (Matos, 2008) e Porto Alegre (Ferreira, 2009).

A categoria, além disso, corre riscos adicionais por um déficit crônico de segurança, sendo alvo atrativo de roubos e assaltos (Paes-Machado \& Riccio-Oliveira, 2009). Se, contudo, a falta de proteção policial é um fator de risco, também seria o abuso de autoridade da mesma instituição em relação aos motoboys. Os autores relacionam o fato com a estigmatização sofrida pelos motociclistas profissionais, que são constantemente associados a crimes violentos e tráfico de drogas. Castro (2010) encontrou que, aliado ao preconceito de que são alvo, esses trabalhadores ainda precisam lidar com a precariedade das condições de trabalho e o alto risco da profissão. Seriam, por isso, propensos ao adoecimento psíquico e dificilmente encontrariam realização no trabalho, mantendo-se nele como forma de subsistência. Diniz, Assunção e Lima (2005), afirmaram ainda que não só a sociedade civil é intolerante em relação aos motoboys, mas também os próprios pesquisadores, ao explicarem seus acidentes de trabalho com base em uma "ideologia do ato inseguro". Nessa perspectiva, os motociclistas seriam culpabilizados por apresentarem um comportamento perigoso, descrito em termos como “'imprudência', 'ousadia', 'irresponsabilidade', 'incivilidade', 'prazer por fortes emoções’ etc.” (p. 906).
Independentemente da variedade de abordagens, uma pergunta é transversal aos estudos sobre motociclistas profissionais: por que, apesar do risco e precariedade, essa ainda é a escolha profissional de muitos? Como vimos, as causas econômicas figuram entre os principais elementos explicativos da entrada nesse campo de trabalho. A contratação em serviços de entrega explodiu e passou a absorver uma mão de obra barata, até então desempregada, masculina e de baixa escolaridade (Ferreira, 2009; Matos, 2008; Paes-Machado \& Riccio-Oliveira, 2009; Silva et al., 2008).

Problematizando a ideia de que esses homens, por conta de sua condição socioeconômica, se vinculariam à profissão apenas por falta de outras opções de trabalho, Castro (2010) afirma que "muitas pessoas que gostavam de andar de moto se vincularam à profissão como uma possibilidade de continuar fazendo o que mais gostam na vida: andar de moto e conseguir uma renda" (p. 161). Seriam, portanto, sujeitos ativos em suas escolhas e em sua apropriação tanto do trabalho quanto do motociclismo. Mas por que são homens, e não mulheres de baixa renda, os que aceitam vivenciar os riscos da moto-entrega em troca da remuneração e pelo "prazer de pilotar"? Julgamos, neste ponto, contar com indícios o bastante de que a construção social das masculinidades pode ser um fator relevante na determinação das práticas de motoboys e motociclistas em geral.

\section{Identidades Masculinas}

Ao considerarmos a condição do motociclista profissional, nos colocamos diante de uma relação imbricada entre dois universos: o motociclismo e as masculinidades. O primeiro ponto a reconhecer, entretanto, é que este encontro é configurado não apenas objetivamente, mas também como um espaço subjetivo masculinizado.

Não parece ser por acaso que os elementos constituintes do estereótipo negativo dos motoboys descrito por Diniz et al. (2005) ("imprudência", "ousadia”, "irresponsabilidade", "incivilidade" e "prazer por fortes emoções") coincidam tão estreitamente com valores e comportamentos historicamente atribuídos ao masculino (Con- 
nell, 1997; Keijzer, 1998; Kimmel, 1998; Olavarría, 2004). No mesmo sentido, acreditamos já estar evidente que os laços de irmandade (brotherhood) estabelecidos com certa variabilidade entre os membros de motoclubes têm em comum o fato de serem elos de cooperação entre irmãos, quer dizer, entre homens. O universo do motociclismo está permeado por grupos compostos por homens que têm a moto como elemento central de identificação.

Ao contrário do que seríamos levados a pensar sob a perspectiva do ato inseguro, crucial para a inauguração da Psicologia do Trânsito e da implementação do processo de avaliação psicológica de condutores no país (Diniz et al., 2005; Silva \& Günther, 2009), uma hipótese possível é a de que o indivíduo não se comporta no contexto do trânsito apenas em função de suas características idiossincráticas, personalidade ou tendências psicobiológicas, mas também enquanto membro de categorias sociais que o ultrapassam e das quais sente que faz parte.

Esses pressupostos, que não são de todo estranhos a uma série de estudos citados, foram sistematizados de maneira específica por Henri Tajfel $(1982,1983)$ em sua Teoria da Identidade Social (Amâncio, 1997; Deschamps \& Moliner, 2009). A relevância da teoria reside em permitir operacionalizar conceitualmente a articulação entre o psicológico e o sociológico, quer dizer, da relação entre o si-mesmo e o reconhecimento de pertenças grupais.

Para Tajfel (1983), a identidade social pode ser definida como "aquela parcela do autoconceito dum indivíduo que deriva do seu conhecimento da sua pertença a um grupo (ou grupos) social, juntamente com o significado emocional e de valor associado àquela pertença" (p. 290). Conjuga, assim, de um a três elementos: cognitivo, o conhecimento de uma pertença, avaliativo, uma conotação de valor positivo ou negativo do grupo e/ou de sua pertença a ele e, por fim, um investimento emocional em relação ao próprio grupo ou aos grupos com os quais se percebe ter relações.

A identidade não é, pois, aquilo que se "é" ou algo que se "tem" de forma estável, mas um "um fenômeno subjetivo e dinâmico resultante de uma dupla constatação de semelhanças e de diferenças entre si mesmo, os outros e alguns grupos" (Deschamps \& Moliner, 2009, p. 14). Os agentes sociais, dessa forma, se integram num espaço social não só através do reconhecimento de uma pertença, mas, ao se reconhecerem semelhantes, buscam situar-se num lugar específico, se diferenciando tanto de outros grupos de não pertença quanto de forma individualmente diferenciada (Deschamps \& Moliner, 2009; Tajfel, 1982, 1983). A noção de identidade, que, segundo Tajfel (1983), é propositalmente vaga e flexível, nos é útil na medida em que permite o estudo integrado desde a filiação a um grupo que mantém interações face a face (como é o caso dos motoboys) até a pertença a categorias sociais mais amplas (no caso, aos motociclistas e ao gênero masculino).

É, portanto, em uma relação de alteridade que os sujeitos constroem sua identidade num universo social segmentado em grupos, alguns dos quais sentem fazer parte, outros dos quais se diferenciam. Em outros termos, os componentes da identidade social, sobre os quais se constata semelhanças e diferenças, são indissociáveis (Deschamps \& Moliner, 2009), ou interdependentes, adquirindo significado através da comparação social (Amâncio, 1997).

Se os atores sociais têm, contudo, uma relação de interdependência, esta não se dá necessariamente de maneira simétrica (Amâncio, 1997; Deschamps \& Moliner, 2009). Nas relações intersexo, por exemplo, a diferenciação entre os gêneros e o consenso construído historicamente sobre os estereótipos sexuais se dará de forma claramente desigual (Amâncio, 1997).

Para nossos propósitos, porém, mais do que reconhecer que há uma assimetria em relação a homens e mulheres, interessa compreender como se dão, dentro do próprio universo masculino, as relações entre as categorias que o compõem internamente, entre diferentes versões de masculinidade (Kimmel, 1998). Como afirmou Keijzer (1998), afinal, se faz necessário "analisar também a forma com que criamos relações de poder e dominação entre os homens" (p. 209).

Além disso, tornar-se homem acarreta em uma série de pressões e limites em suas possi- 
bilidades de autoconhecimento, autocuidado e encontro com outros e outras (Keijzer, 1998; Kimmel, 1998; Olavarría, 2004). "Se designa aos homens que para chegar a ser adultos em plenitude devem submeter-se a uma ortopedia, ser homem requer uma aprendizagem. É um caminho difícil, mas tem suas recompensas" (Olavarría, 2004, p. 237).

Ao focalizar homens motociclistas, o presente trabalho pretende contribuir com a compreensão da construção social do alto índice de motorização e mortalidade entre a população masculina em geral e entre motociclistas profissionais em específico. Nesse sentido, pretendeu-se identificar e analisar como motoboys de Belo Horizonte/MG concebem diferentes versões de masculinidade e que relações essas podem manter com a forma como se veem, se sentem e se comportam como motociclistas.

\section{Método}

Trata-se de um estudo qualitativo de caráter exploratório.

\section{Participantes}

Com vista a alcançar os propósitos da investigação, foram realizadas, entre abril e junho de 2015, dez entrevistas com motoboys moradores de Belo Horizonte/MG. Os sujeitos foram selecionados segundo seu interesse e disponibilidade em participar da pesquisa e contatados através da técnica de bola de neve, em que cada entrevistado indicava outros possíveis interessados em participar da pesquisa.

Os sujeitos, todos homens, formam um grupo heterogêneo, com práticas e inserções profissionais diversas (Tabela 1). A idade dos entrevistados variou entre 27 e 50 anos e a experiência relatada como motofretista foi desde 2 até 19 anos. Quanto à experiência como motociclistas, as respostas variaram desde 2 anos e 7 meses até 36 anos. Seis afirmaram ser esta sua única fonte de renda, dois relataram trabalhar como motoboys em dois turnos e dois afirmaram ter outro emprego fixo. Apenas três deles disseram ser solteiros. Os nomes atribuídos aos entrevistados são fictícios.

\section{Tabela 1}

Perfil dos Entrevistados

\begin{tabular}{|c|c|c|c|c|c|}
\hline Entrevistado & Idade & $\begin{array}{c}\text { Experiência } \\
\text { como motociclista }\end{array}$ & $\begin{array}{l}\text { Experiência } \\
\text { como motoboy }\end{array}$ & $\begin{array}{c}\text { Outro } \\
\text { emprego }\end{array}$ & $\begin{array}{c}\text { Estado } \\
\text { civil }\end{array}$ \\
\hline Davi & 40 anos & 22 anos & 18 anos & Sim & Casado \\
\hline Gustavo & 30 anos & 18 anos & 4 anos & Sim* & Casado \\
\hline Jorge & 43 anos & 35 anos & 6 anos & Não & Casado \\
\hline Lucas & 29 anos & 17 anos & 8 anos & Não & Solteiro \\
\hline Marcos & 32 anos & 2 anos e 7 meses & 2 anos e 6 meses & Sim & Casado \\
\hline Natan & 30 anos & 9 anos e 3 meses & 9 anos & Sim* & Casado \\
\hline Nicolas & 50 anos & 36 anos & 19 anos & Não & Casado \\
\hline Nelson & 26 anos & 8 anos & 2 anos & Não & Solteiro \\
\hline Renan & 40 anos & 26 anos & 15 anos & Não & Solteiro \\
\hline Renato & 27 anos & 14 anos & 7 anos & Não & Casado \\
\hline
\end{tabular}

Nota. *Possuem dois empregos como motoboys. 


\section{Instrumentos}

Optamos por realizar entrevistas semiestruturadas por entendermos ser conveniente seu caráter versátil e, ao mesmo tempo, permitir um direcionamento mínimo que garantisse a comparabilidade das repostas. O roteiro de entrevista contou com nove perguntas e buscou acessar como os sujeitos representam e avaliam a si mesmos, seus grupos de pertença e grupos de não-pertença: 1. Como você prefere ser chamado: Motociclista ou motoqueiro? Motoboy ou motofretista? Por quê? 2. É comum ouvir dizer que os motociclistas têm uma certa parceria entre si. É verdade? 3. Como você identifica um bom motociclista? Por quê? 4. E um mau motociclista? Por quê? 5. Você se considera um bom motociclista? Por quê? 6. Como os outros motoristas agem em relação a você no trânsito? 7 . Você nota alguma diferença entre motoboys e demais motociclistas? Quais? 8. Como é a relação com eles? 9. Você já presenciou muitos acidentes? Por que acha que acontecem?

\section{Procedimentos}

Coleta de Dados. Com o devido consentimento dos informantes, as entrevistas foram registradas através do gravador e posteriormente transcritas pelo próprio pesquisador que realizou as entrevistas, de modo a propiciar a reprodução textual o mais fiel possível das entrevistas. Além disso, o próprio trabalho de transcrição permitiu a formulação de primeiras impressões e apostas que se mostraram úteis na etapa de codificação do texto.

Análise de Dados. Depois de transcritas, as entrevistas foram analisadas através da técnica de análise de conteúdo temática (Bardin, 1977/2011), com o auxílio do software Nvivo7. Para a codificação e interpretação do conteúdo das entrevistas, optamos pela enumeração da quantidade de fontes em que ocorre cada conjunto de significados e por sua articulação na apresentação dos resultados. A técnica nos foi útil na medida em que possibilitou, através da análise rigorosa do texto, uma reorganização metódica do mesmo que facilitou a apreensão dos processos psicossociológicos que permeavam as construções de significado pelos entrevistados.

\section{Procedimentos Éticos}

O estudo foi aprovado pelo Comitê de Ética em Pesquisa da Universidade Federal de Minas Gerais conforme parecer 648.350 de 16 de abril de 2014. Todos os entrevistados participaram voluntariamente mediante assinatura de Termo de Consentimento Livre e Esclarecido.

\section{Resultados e Discussão}

A análise de conteúdo das entrevistas gerou um total de vinte e dois códigos, organizados em quatro categorias: Motoqueiros profissionais, Motoqueiros amadores, Motoristas e Agentes reguladores (Figura 1). Considerando a natureza qualitativa do trabalho e dos dados obtidos, realizamos a seguir uma exposição teoricamente orientada dos resultados.

\section{Nós: Motoqueiros Profissionais e Motoqueiros Amadores}

Motociclismo e profissão compõem, para os entrevistados, duas esferas intimamente relacionadas, que se interpenetram e muitas vezes se confundem. Seja no percurso na profissão, seja na forma como se nomeiam e se identificam entre si, muitas vezes é tênue a fronteira entre lazer e trabalho. Em alguns momentos, porém, serão justamente esses os polos de diferenciação e valorização entre diferentes motociclistas.

Ao invés de se identificarem como um dos grupos, dentre outros, compostos por motociclistas, oito dos dez entrevistados se nomearam espontaneamente, pelo menos uma vez, como "motoqueiros". Nesse sentido, trabalhar também é um lazer, ser motoboy é receber para exercer seu hobby. "O que me chamou mais para essa profissão foi isso, foi um lazer, eu comecei como um lazer. Deslocava para ir trabalhar, minha profissão antes não era essa profissão" (Nicolas).

Isso não quer dizer, entretanto, que seja irrelevante, para os entrevistados, se diferenciarem dos demais motoqueiros. Para aqueles que vivenciam motociclismo e profissão como duas faces da mesma moeda, $\mathrm{o}$ amadorismo significa uma falta. $\mathrm{O}$ "motoqueiro de verdade" é aquele que trabalha com a motocicleta, tem laços firmes de solidariedade, é responsável, habilidoso e experiente. 


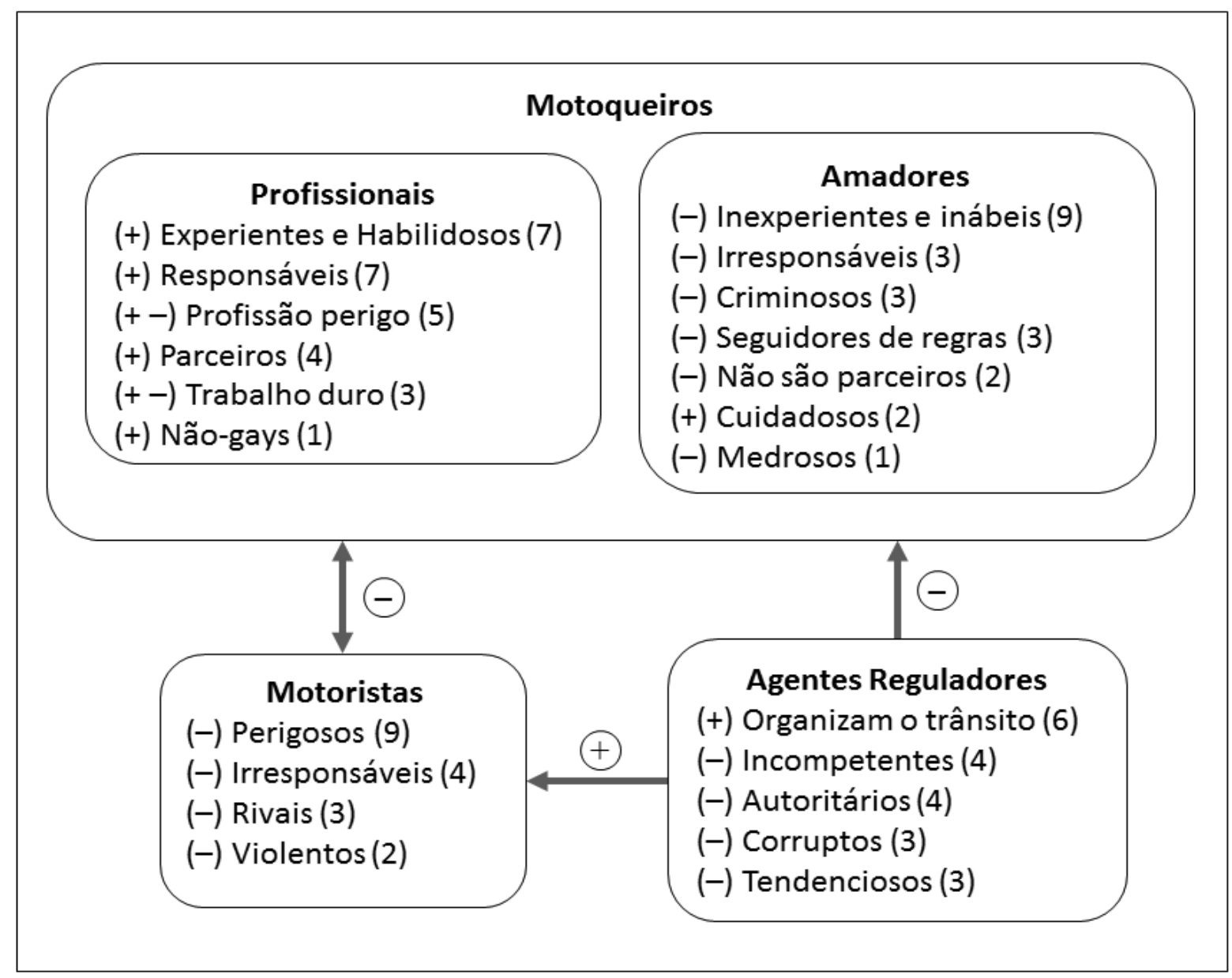

Figura 1. Características e relações atribuídas aos grupos formados por Motoqueiros Profissionais, Motoqueiros Amadores, Motoristas e Agentes Reguladores. Cada código é precedido de um sinal positivo ou negativo, que indica sua valorização/ desvalorização, a presença de ambos remete a uma valorização ambígua. A numeração entre parênteses informa a quantidade de entrevistas em que cada código se faz presente. As setas com sinalização positiva e negativa representam uma relação harmoniosa ou conflituosa entre os grupos, respectivamente.

A negativação generalizada que os outros fariam dos motoqueiros passa, para os entrevistados, por um desconhecimento de suas diferenças internas: "Eu acho que pegaram a gente como bode expiatório" (Marcos), quer dizer, como destinatários de características que não lhes pertencem. "É igual o velho ditado, eles julgam os justos pelos pecadores" (Renato).

A distinção entre motoqueiros é alcançada, assim, através da atribuição de características polarizadas a duas classes de motoqueiros, hierarquicamente organizadas: os Motoqueiros Profissionais e os Motoqueiros Amadores. A resposta a cada conteúdo negativo atribuído ao grupo dos motoqueiros é bastante similar: são os motoqueiros amadores, os não-motoboys, que acabam "queimando o filme de quem tá tranquilo, de quem tá trabalhando" (Lucas).
Ser habilidoso na condução da motocicleta é essencial ao bom motoqueiro e tem relação direta com sua experiência no trânsito, pois é apenas através dela que se adquire a "maldade" necessária a este ambiente hostil. Não por acaso, os motoqueiros profissionais são Experientes e habilidosos (7) e os motoqueiros amadores, Inexperientes e inábeis (9).

Tem uns que não tem experiência nenhuma, esses são os perigosos. Você não tem maldade no trânsito. Que nem outro dia, um carro foi me pressionando ... Se eu fosse esses meninos que não tivesse experiência, você tinha que ver, já tinha batido. (Jorge)

Além da perícia, evitar um acidente envolveria um maior senso de responsabilidade. $\mathrm{O}$ marcador da diferença não é outro senão a profissão: motoboys são Responsáveis (7) e os ama- 
dores, Irresponsáveis (3). "É uma responsabilidade muito grande, entendeu? Não tem como. O camarada te passa a rota, você tem que dar conta dela. Você tem que assumir uma responsabilidade, ... entregar o serviço" (Nicolas).

Em função de diferentes inserções no trânsito e no universo do motociclismo, a solidariedade entre motoqueiros também não é distribuída igualmente. Segundo os entrevistados, motoboys têm laços firmes de irmandade e são Parceiros (4) uns dos outros, mas não se pode contar da mesma forma com os motoqueiros amadores, esses Não parceiros (2). "Quando é o motoqueiro mesmo, o cara que trabalha mesmo, ele viu um motoqueiro parado, ele para, véi. Aí o outro pode ser que pare, pode ser que não pare, entendeu?" (Natan).

Da mesma forma, o baú da moto, equipamento básico de trabalho, é o marcador da distinção entre motoqueiros Criminosos (3), pertencentes ao grupo formado pelos amadores, $\mathrm{e}$ os profissionais. "A criminalidade geralmente o cara vai de dois, com garupeiro. Às vezes você está com baú, o cara tá te tratando como bandido" (Davi).

As características que os motoqueiros profissionais atribuem a si mesmos e aos motoqueiros amadores, assim, podem ser lidas em relação de dependência com aspectos negativos que julgam ser amplamente compartilhados sobre seu grupo de pertença. É nesse sentido que a irresponsabilidade e criminalidade percebidas entre aquilo que "dizem sobre nós" pode encontrar eco na atribuição de características negativas aos motoqueiros amadores. Apesar de compartilharem da mesma pertença em muitas ocasiões, a manutenção cognitiva de duas classes suficientemente distintas de motoqueiros facilita a positivação de si mesmo e do próprio grupo através do deslocamento autocondescendente da ameaça oferecida pelos conteúdos negativos.

Mas nem todos os juízos comparativos são desvantajosos para o motoqueiro amador. Dois dos entrevistados reconhecem que estes seriam mais Cuidadosos (2) do que quem Trabalha duro (3) em uma Profissão-perigo (5). Ao contrário do amador, entretanto, o motoqueiro profissional corre mais riscos justamente porque usa sua ha- bilidade e experiência a favor da responsabilidade com o trabalho. Será esta mesma habilidade a responsável por minimizar os riscos inerentes à profissão (e não a seu grupo de pertença).

$O$ motociclista é mais tranquilo, ele tem mais o tempo dele ali, ele não precisa passar no corredor, né? Usa a moto como diversão, como passeio. E o motoboy já é diferente, ele precisa entrar nos corredores e furar sinal mesmo, tem hora que acontece, passar no amarelo, por causa do tempo. (Gustavo)

Associados ao maior cuidado no trânsito, os motoqueiros amadores acabam se submetendo demais à legislação do trânsito. São Seguidores de regras (3) e até um pouco Medrosos (1). $\mathrm{O}$ bom motoqueiro não é somente responsável, é aquele que sabe a hora de transgredir uma regra ou outra e tem a coragem de assumir riscos (para o seu próprio bem).

Eu acho que moto anda é na frente. Se você andar atrás de ônibus, de carro, de... As chances de sofrer um acidente é muito maior que você andar lá no corredor. Você precisa enxergar o chão, senão você envolve em acidente mesmo. (Davi)

Ainda que represente um "perigo" no trânsito, portanto, a inabilidade do motoqueiro amador é acompanhada por um maior cuidado, medo e obediência às regras. Há indícios o bastante para suspeitar que, para os motoboys entrevistados, o motoqueiro amador não é viril o bastante e, justamente por isso, não pode ser bom condutor.

Por fim, as exigências da profissão são tais que, segundo os entrevistados, repelem naturalmente o homem homossexual. A heterossexualidade, afinal, é peça chave da masculinidade hegemônica e esta é ingrediente fundamental do bom motoqueiro. O motoqueiro de verdade é o Não-gay (1).

Eu tava conversando esses dias aí, [risos] eu racho de rir, eu falei assim ... Vocês já viram algum motoboy gay? [risos]. Eu nunca vi. Bom, tem enrustido né, mas . . Você já reparou que na profissão eles não procuram ser motoboy? (Davi)

Neste panorama, os motoboys se sobressaem como modelo ideal do bom motoqueiro: são 
responsáveis, experientes e habilidosos, parceiros entre si e não são medrosos como seus pares amadores. Correm muitos riscos no dia a dia, mas não por falta de perícia e sim por trabalharem duro em uma profissão perigo. Uma atividade penosa, portanto, que lhes permite atestar sua virilidade através do trabalho e se afastar de referências de fragilidade como o homem superzeloso e o homossexual. $\mathrm{O}$ "motoqueiro de verdade" é um homem de verdade.

\section{Eles: Motoristas e Agentes Reguladores}

Tratamos até aqui da forma como os entrevistados concebem e articulam o motociclismo e a profissão, como se diferenciam internamente e concebem os diferentes usos e usuários da motocicleta. Outra fonte privilegiada de informação sobre como as referências de masculinidade participam da construção identitária dos motociclistas profissionais será a forma como se comparam e diferenciam de outros grupos masculinos no contexto do trânsito. Nesse enquadramento, o incontestável risco oferecido pelo trânsito encontra correspondência na hostilidade oferecida por motoristas e na complacência e ineficiência dos agentes reguladores do trânsito.

Ao se diferenciarem de grupos que consideram relevantes, a distinção entre motoqueiros profissionais e amadores é circunstancialmente abandonada e o próprio grupo de pertença, os motoqueiros, se reveste de relativa maior homogeneidade. Independentemente se por profissão ou lazer, locomover-se em duas rodas é saber-se em situação desprivilegiada perante outro homens.

Os motoristas são um grupo formado por uma ampla gama de sujeitos: taxistas, motoristas de carros, caminhões, carretas, ônibus, etc. Compartilham, entretanto, a posição de Rivais (3) em relação aos motoqueiros. Na disputa cotidiana por espaço no trânsito, além de serem Violentos (2) e Irresponsáveis (4), esses sujeitos dirigem veículos maiores e mais potentes e por isso são mais Perigosos (9).

"Eles não respeitam muito motoqueiro não. Ônibus mesmo, você tá doido. Ônibus e caminhão, você pode sair mesmo. Se tiver vindo atrás de você, você encosta, meu filho, e deixa ir embora" (Natan).

As implicações comportamentais para os motoqueiros são claras: os motoristas são um grupo a ser evitado constantemente no trânsito. O bom motoqueiro é aquele sempre alerta ao perigo muitas vezes mortal oferecido pelos motoristas. Contra a irresponsabilidade e violência do motorista, o motoqueiro conta apenas com sua habilidade, experiência e destacado senso de responsabilidade.

Os Agentes Reguladores, por sua vez, são uma categoria difusa representada por uma grande variedade daqueles que os entrevistados reconhecem como representantes da ordem pública: políticos, membros de órgãos fiscalizadores, da polícia, do judiciário, da "administração do governo", etc. Para seis sujeitos, os agentes reguladores exercem uma função essencial, eles Organizam o trânsito (6), instituem as leis e normas que regem as vias e averíguam o seu cumprimento. Nesse sentido, os problemas do trânsito seriam fruto do desrespeito às leis.

"A maioria dos acidentes acontecem porque não respeitam a velocidade, placa, preferência, por isso. Se todo mundo respeitasse velocidade, a legislação de trânsito, não tinha esse proble$m a "$ (Gustavo).

Obedecer às normas, entretanto, encontra obstáculo na desconfiança nutrida em relação aos agentes reguladores. Apesar de reconhecer sua importância, o motoqueiro profissional tem ciência dos riscos da ingerência externa à sua própria profissão. Tudo correria bem se os agentes reguladores não fossem Corruptos (3).

"O nosso trânsito é muito confuso, mal sinalizado, muito na gambiarra, asfalto cheio de buraco. Dá pra ver que asfalto de má qualidade pra sobrar uma verbinha aqui, outra acolá" (Marcos).

Os agentes reguladores também seriam $A u$ toritários (4), tolhendo o direito à autodeterminação dos motoboys e os coagindo através de multas e demais sanções.

Eu não sou a favor de ninguém me obrigar a fazer nada. . . Se eu der uma louca na minha cabeça e eu quiser morrer em cima da minha moto, eu não posso me dar ao 
luxo de andar sem a anteninha, porque senão eu não posso morrer em paz. Além de morrer, eu vou ter que pagar uma multa [risos]. (Lucas)

Os agentes reguladores, além de limitarem a liberdade dos motoqueiros e agirem em interesse próprio, também são Tendenciosos (3) na resolução de conflitos no trânsito, sempre em favor dos motoristas e nunca dos motoqueiros.

"[Em] noventa por cento dos acidentes, motoqueiro tá errado, infelizmente, tá errado. Por mais que o cara não queira estar, quando chegar a autoridade, motoqueiro tá errado" (Renato).

Para o motoqueiro de verdade, aquele que conhece as ruas e o trânsito como a palma de sua mão, o agente regulador é um personagem quase cômico: um funcionário público, deslocado da realidade por estar sempre preso em um gabinete, transformando em leis suas fantasias. São abundantes os relatos, por exemplo, da audácia de um instrutor inexperiente, que "não conhece de moto", querer ensinar algo para quem mais conhece de seu trabalho: o próprio motoboy. Os agentes reguladores, na verdade, são uns Incompetentes (4).

Eu acho que o governo . . . simplesmente utilizou os números, não viu o que deveria ser feito, o que acontece ... se os motoboys vão ter que parar de trabalhar pra fazer os tal dos cursos que eles exigem ... Não quis ver. (Marcos)

Seja por ignorância ou má fé, portanto, os agentes reguladores são os únicos capazes de colocar obstáculos à liberdade conquistada através da motocicleta como veículo e instrumento de trabalho. Somada à hostilidade dos motoristas, sua ingerência terá efeitos nocivos em todo o trânsito, resultando em um campo de inimizades e desregramento. Frente a um âmbito público viciado, portanto, o "motoqueiro de verdade" (o motoboy) conta com um elevado senso moral, sendo obrigado às vezes a desrespeitar algumas normas equivocadas em prol daquilo que sabe ser o certo.

Apesar de reconhecerem conviver com muitos riscos no trânsito, os entrevistados em grande medida se julgam invulneráveis a eles. Em um contexto onde é evidente a alta mortalidade de motociclistas, a alocação do risco à própria profissão ou a um grupo externo, tem uma aguda implicação psicossociológica: o risco que se corre não é responsabilidade de si mesmo ou do próprio grupo. A atribuição do perigo a uma instância externa pode, assim, catalisar a expurgação de uma de suas piores consequências possíveis: a assimilação do endogrupo a uma referência de fragilidade e incompetência, ou seja, a um modelo subalterno de masculinidade.

Pelo contrário, mais que um trabalhador submetido a uma situação precária e alienante que, em troca de um rendimento mensal, pode lhe custar a vida ou causar sérios danos a sua saúde, o motoboy se reconhece como um homem que dribla a morte diariamente e tem pleno controle de seu destino. Acreditamos, neste ponto, não serem necessárias mais evidências para assumir que tratamos, neste trabalho, não apenas de indivíduos se esforçando por valorizarem a si mesmos e a seu próprio grupo, mas de homens se empenhando em provar seu valor como homens e perante outros homens.

Em ambos os casos, portanto, tanto no quadro de oposição motoqueiros profissionais versus amadores quanto motoqueiros versus motoristas e agentes reguladores, são as distinções de gênero o critério subjacente de diferenciação, transversal às atribuições realizadas a cada um dos grupos. Ser motoqueiro é uma identidade generificada.

\section{Considerações Finais}

Em um contexto social hostil e competitivo como o trânsito, organizado, segundo os entrevistados, por agentes reguladores incompetentes, autoritários e corruptos, os motoboys se julgam ameaçados por motoristas irresponsáveis e violentos, com quem têm relação mútua de rivalidade. O resultado é um quadro de comparação em que os motociclistas, apesar de contarem com baixo estatuto em relação a outros atores do trânsito, são os únicos, segundo eles mesmos, definidos por características e condutas aprováveis.

A categorização dos diversos atores que participam do trânsito, nesse panorama mais ge- 
ral, se aproxima do modelo proposto por Tajfel (1982, 1983). Como vimos, a "hostilidade" que, para os entrevistados, caracteriza o trânsito não é aleatoriamente distribuída entre indivíduos isolados, mas principalmente entre motoqueiros e motoristas (com a conivência dos agentes reguladores). Trata-se, pois, de um conflito intergrupal em que os entrevistados sentem que são tratados segundo sua pertença a um grupo minoritário, e não por suas características idiossincráticas. Nesse sentido, são evidenciadas as identidades sociais dos sujeitos, se exageram as semelhanças entre os membros de um mesmo grupo e, ao mesmo tempo, se amenizam as similaridades entre membros de grupos diferentes. Motoristas e agentes reguladores são apresentados como não-motoqueiros, grupos revestidos de características polarizadas negativas frente a um endogrupo responsável, habilidoso e dedicado. Ganham espaço, assim, os efeitos de estereotipia e autoestereotipia.

Ainda que motoqueiros profissionais e amadores compartilhem da pertença ao motociclismo, entretanto, as atribuições diferenciais realizadas a estes últimos têm valor estratégico ao circunscrever os traços negativos atribuídos aos motoqueiros a um subgrupo de não-pertença. Se as pessoas acreditam que os motoboys são culpados pela violência e caos no trânsito, é porque não entendem as diferenças entre o trabalhador e o irresponsável ou criminoso, e "julgam os justos pelos pecadores".

A figura do motociclista amador, nesse caso, é a de um homem sem autocontrole, um fora da lei inconsequente que coloca a si mesmo e aos outros em risco. Ao mesmo tempo, entretanto, o amador é também um homem fraco e inseguro que não tem os mesmos reflexos do profissional para se manter vivo no dia a dia do trânsito. Falta-lhe a experiência e a "maldade" necessárias. Mais ainda, falta-lhe coragem. É, portanto, másculo demais, pois incontrolável e bestial e masculino de menos, pois frágil, medroso e cuidadoso.

Os entrevistados demonstraram, assim, compartilhar de um ideal permeado por valores masculinos: um sujeito competente, responsável, heterossexual, ousado, destemido, indepen- dente e dominante. O "bom motoqueiro" não é apenas um bom condutor e bom trabalhador, é um homem excepcional.

Ainda que saiba ocupar uma posição inferior na escala social do trânsito, a mudança nos critérios de comparação permitirá ao motoboy positivar sua pertença ao grupo. Se sentem que não podem competir com outros homens com maior influência e poder de decisão (os agentes reguladores), nem com o conforto e privilégio daqueles que dirigem veículos maiores e mais potentes (os motoristas), os motoboys ainda podem vencê-los na proximidade psicológica a um ideal hegemônico de masculinidade.

Como afirmou Tajfel (1982), em um contexto concreto de comparação e conflito intergrupo, não se trata de uma valorização "autista" da própria pertença. Ao invés de distorções grosseiras da realidade visando o autofavorecimento, as diferenciações grupais por parte dos entrevistados revelaram um uso tático de representações identitárias, uma abertura à negociação de referências e envolveram uma série de concessões. Mais que uma autovalorização geral e irrestrita do próprio grupo, os entrevistados em seu conjunto pareceram compartilhar de uma escolha por aquilo que realmente interessa, em uma arena onde se julgam estar em condições de competir: a aquisição bem-sucedida de masculinidade.

\section{Referências}

Amâncio, L. (1997). Identidade social e relações intergrupais. In J. Vala \& M. B. Monteiro (Eds.), Psicologia social (3. ed., pp. 287-307). Lisboa: Fundação Calouste Gulbenkian.

Bardin, L. (2011). Análise de conteúdo (5. ed., L. A. Reto \& A. Pinheiro, Trads.). Lisboa: Edições 70. (Original publicado em 1977)

Berger, M. L. (1992). The Car's Impact on the American Family. In M. Wachs \& M. Crawfor (Eds.), The car and the city: The built environment, and daily urban life (pp. 57-74). Detroit, MI: The University of Michigan Press.

Castro, M. F. (2010). Os motoboys de São Paulo e a produção de táticas e estratégias na realização das práticas cotidianas (Tese de doutorado, Instituto de Psicologia, Universidade de São Paulo, SP, Brasil). 
Connell, R. W. (1997). La organización social de la masculinidad (O. Jiménez, Trans.). In T. Valdés \& J. Olavarría (Eds.), Ediciones de las Mujeres: Vol. 24: Masculinidad/es: poder y crisis (pp. 3148). Santiago de Chile: ISIS-FLACSO.

Deschamps, J.-C., \& Moliner, P. (2009). A identidade em psicologia social: Dos processos identitários às representações sociais (L. M. E. Orth, Trad.). Petrópolis, RJ: Vozes.

Diniz, E. P. H., Assunção, A. A., \& Lima, F. P. A. (2005). Prevenção de acidentes: O reconhecimento das estratégias operatórias dos motociclistas profissionais como base para a negociação de acordo coletivo. Ciência \& Saúde Coletiva, 10(4), 905-916. doi: 10.1590/S141381232005000400014

Fernandes, H. S. (2012). A relação entre as Identidades Territoriais e a "nova urbanidade": O caso das manifestações identitárias dos grupos de motociclistas em Salvador, Bahia (Dissertação de mestrado, Instituto de Geociências, Universidade Federal da Bahia, Salvador, BA, Brasil).

Ferreira, F. F. (2009). Fatores de risco em acidentes envolvendo motocicletas em vias urbanas: $A$ percepção dos condutores profissionais (Dissertação de mestrado, Programa de Pós-Graduação em Engenharia de Produção, Universidade Federal do Rio Grande do Sul, Porto Alegre, RS, Brasil).

Figliuzzi, A. (2008). Homens sobre rodas: Representações de masculinidades nas páginas da revista Quatro Rodas (Dissertação de Mestrado, Faculdade de Educação, Universidade Federal do Rio Grande do Sul, Porto Alegre, RS, Brasil).

Hopper, C. B., \& Moore, J. (1983). Hell on Wheels: The outlaw motorcycle gangs. Journal of American Culture, 6, 58-64. doi:10.1111/j.1542734X.1983.0602_58.x

Hopper, C. B., \& Moore, J. (1990). Women in outlaw motorcycle gangs. Journal of Contemporary Ethnography, 18(4), 363-387. doi: $10.1177 / 089124190018004001$

Keijzer, B. (1998). El varón como factor de riesgo: masculinidad, salud mental y salud reproductiva. In E. Tuñón (Ed.), Género y salud en el Sureste de México (pp. 199-219). Villahermosa, MX: ECOSUR.

Kimmel, M. S. (1998). A produção simultânea de masculinidades hegemônicas e subalternas. Horizontes Antropológicos, 4(9), 103-117. doi: 10.1590/S0104-71831998000200007
Lara, A. A. (2007). Representação de mulher nos comerciais de automóveis: Garota é apenas equipamento opcional (Dissertação de mestrado, Faculdade de Comunicação, Universidade de Brasília, DF, Brasil).

Luz, C. C. R. (2009). Sobre duas rodas: Emoções e consumo no motociclismo (Dissertação de mestrado, Instituto de Filosofia e Ciências Humanas, Universidade do Estado do Rio de Janeiro, RJ, Brasil).

Matos, R. H. F. (2008). Estudo exploratório das relações de trabalho como fator de influência do comportamento humano no trânsito: Caso do motofrete (Dissertação de mestrado, Faculdade de Tecnologia, Universidade de Brasília, DF, Brasil).

Olavarría, J. (2004). Masculinidades, poderes y vulnerabilidades. In A. V. Alvarez (Ed.), Chile 2003-2004: los nuevos escenarios (inter) nacionales (pp. 227-244). Santiago, Chile: FLACSO-Chile.

Paes-Machado, E., \& Riccio-Oliveira, M. A. (2009). $\mathrm{O}$ jogo de esconde-esconde: Trabalho perigoso e ação social defensiva entre motoboys de Salvador. Revista Brasileira de Ciências Sociais, 24(70), 91-184. doi: 10.1590/S010269092009000200006

Rodrigues, C. S., Ladeira, R. M., Pereira, J. C., \& Paula, I. M. (Eds.). (2005). Saúde em trânsito: Pesquisa de acompanhamento de vítimas de acidentes de trânsito em Belo Horizonte. Belo Horizonte, MG: Prefeitura de Belo Horizonte.

Scharff, V. (1992). Gender, electricity, and automobility. In M. Wachs \& M. Crawfor (Eds.), The car and the city: The built environment, and daily urban life (pp. 75-85). Detroit, MI: The University of Michigan Press.

Silva, D. W., Andrade, S. M., Soares, D. A., Nunes, E. F. P. A., \& Melchior, R. (2008). Condições de trabalho e riscos no trânsito urbano na ótica de trabalhadores motociclistas. Physis [online], 18(2), 339-360. doi: 10.1590/S010373312008000200008

Silva, F. H. V. C., \& Günther, H. (2009). Psicologia do trânsito no brasil: De onde veio e para onde caminha? Temas em Psicologia, 17(1), 163-175. Recuperado em http://pepsic.bvsalud.org/scielo. php?script $=$ sci_arttext\&pid=S1413-389X20090 $00100014 \& \operatorname{lng}=\mathrm{pt} \& \operatorname{tlng}=\mathrm{pt}$

Souza, L. C. G. (2001). As representações sociais do carro, da velocidade e do risco em jovens 
(Dissertação de mestrado, Instituto de Psicologia, Universidade Federal do Rio de Janeiro, RJ, Brasil).

Tajfel, H. (1982). Grupos humanos e categorias sociais: Estudos em psicologia social (Vol. 1; L. Amâncio, Trad.). Lisboa: Livros Horizonte.

Tajfel, H. (1983). Grupos humanos e categorias sociais: Estudos em psicologia social (Vol. 2; L. Amâncio, Trad.). Lisboa: Livros Horizonte.

Wachs, M. (1992). Men, women, and urban travel: The persistence of separate spheres. In M. Wachs \& M. Crawfor (Eds.), The car and the city: The built environment, and daily urban life (pp. 86-100). Detroit, MI: The University of Michigan Press.
Waiselfisz, J. J. (2013). Mapa da violência 2013: Acidentes de Trânsito e Motocicletas. Rio de Janeiro, RJ: Centro Brasileiro de Estudos Latino-Americanos.

Wolf, D. R. (1991). The rebels: A brotherhood of outlaw bikers. Toronto: University of Toronto Press.
Recebido: $30 / 08 / 2016$

$1^{a}$ revisão: $11 / 04 / 2017$

Aceite final: $21 / 04 / 2017$ 